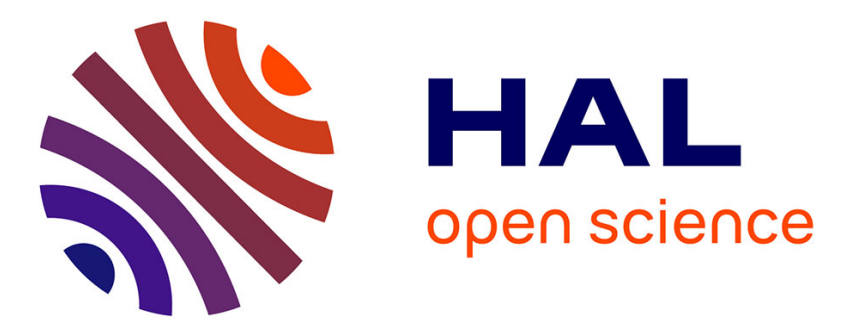

\title{
The initiation and propagation of the fertilization wave in sea urchin eggs
}

Alex Mcdougall, Joanne Shearer, Michael Whitaker

\section{To cite this version:}

Alex Mcdougall, Joanne Shearer, Michael Whitaker. The initiation and propagation of the fertilization wave in sea urchin eggs. Biology of the Cell, 2000, 92 (3-4), pp.205-214. 10.1016/s0248-4900(00)01073x . hal-03025752

\section{HAL Id: hal-03025752 https://hal.science/hal-03025752}

Submitted on 16 Dec 2020

HAL is a multi-disciplinary open access archive for the deposit and dissemination of scientific research documents, whether they are published or not. The documents may come from teaching and research institutions in France or abroad, or from public or private research centers.
L'archive ouverte pluridisciplinaire HAL, est destinée au dépôt et à la diffusion de documents scientifiques de niveau recherche, publiés ou non, émanant des établissements d'enseignement et de recherche français ou étrangers, des laboratoires publics ou privés. 


\title{
The initiation and propagation of the fertilization wave in sea urchin eggs
}

\author{
Alex McDougall, Joanne Shearer, Michael Whitaker ${ }^{\star}$ \\ Department of Physiological Sciences, Medical School, University of Newcastle upon Tyne, Framlington Place, \\ Newcastle upon Tyne NE2 4HH, UK
}

Received 30 May 2000; accepted 7 July 2000

Calcium waves sweep across most eggs of the deuterostome lineage at fertilization. The precise timing of the initiation and propagation of a fertilization calcium wave has been best studied in sea urchin embryos, since the rapid depolarization caused by sperm egg fusion can be detected as a calcium influx using confocal imaging of calcium indicator dyes. The time between sperm egg fusion and the first sign of the calcium increase that constitutes the calcium wave is comparable to the time it takes for the wave to sweep across the egg, once initiated. The latency and rise time of the calcium response is sensitive to inhibitors of the $\operatorname{InsP}_{3}$ signalling pathway, as reported previously. Using calcium green dextran and confocal microscopy, we confirm that the propagation time of the calcium wave is lengthened and that initiation of the calcium wave involves activation of calcium release at hot spots that may represent clusters of calcium release channels, as has been seen in other cell types. (c) 2000 Éditions scientifiques et médicales Elsevier SAS

\section{calcium / wave propagation / inositol triphosphate / phospholipase $\gamma$}

\section{INTRODUCTION}

Fertilization waves are initiated by sperm in sea urchin, starfish, ascidian, frog and mammalian oocytes (Swann and Whitaker, 1986; Speksnijder et al., 1990; Miyazaki et al., 1992; Galione et al., 1993; Stricker, 1995). In all these cases, except ascidian and mammalian oocytes, the generation of the calcium wave is retarded or blocked by inhibitors of the $\mathrm{InsP}_{3}$ receptor

\footnotetext{
*Correspondence and reprints: michael.whitaker@ncl.ac.uk
}

or by blocking phospholipase C activity (Crossley et al., 1991; Nuccitelli et al., 1993; Carroll et al., 1997, 1999; Lee and Shen, 1998; Shearer et al., 1999). In the ascidian, $\mathrm{InsP}_{3}$ receptor antagonists do not block the initial calcium wave (McDougall and Sardet, 1995; Yoshida et al., 1998), but a PLC $\gamma$ antagonist does (Runft and Jaffe, 2000). Conversely, mammalian oocytes are sensitive to $\mathrm{InsP}_{3}$ receptor antagonists (Miyazaki et al., 1992, 1993) but not to the PLC $\gamma$ antagonist (Mehlmann et al., 1998). In the sea urchin and frog egg, phosphoinositide lipid turnover and the generation of $\operatorname{Ins}_{3}$ have been measured and coincide with the calcium wave (Ciapa et al., 1992; Snow et al., 1996; Lee and Shen, 1998). The consensus is that the active phospholipase is PLC $\gamma$; 
PLC $\beta$ may also play a role in the sea urchin egg (Lee and Shen, 1998), though the inhibitor used is not specific for PLC $\beta$ and may also block the ryanodine receptor pathway (Lee et al., 1998). PLC $\gamma$ may in turn be activated by tyrosine kinases of the Src family (Ciapa and Epel, 1991; Shen et al., 1999; Giusti et al., 1999a,b; Glahn et al., 1999; Abassi et al., 2000). How the sperm triggers activation of tyrosine kinases is not known. It may be that an active kinase diffuses from sperm to egg after sperm egg fusion (Swann, 1993; Lawrence et al., 1997; Kyozuka et al., 1998; Runft and Jaffe, 2000). Mammalian oocytes are the exception in their lack of sensitivity at fertilization to inhibitors of tyrosine kinases and PLC $\gamma$ (Mehlmann et al., 1998). In these oocytes, the active messenger passing from sperm to egg at fertilization may be another phosphoinositide-specific phospholipase (Jones et al., 1998, 2000).

The moment of fertilization of the sea urchin egg is marked by a rapid depolarization (Chambers and de Armendi, 1979) that acts as a block to polyspermy (Jaffe, 1976; Whitaker and Steinhardt, 1982). depolarization is due initially to the sudden insertion of sperm cation channels into the egg membrane when sperm and egg fuse (Lynn and Chambers, 1984; Lynn et al., 1988; McCulloh and Chambers, 1992) and is amplified by an influx of calcium through voltage-dependent L-type calcium channels (David et al., 1988; Lynn et al., 1988; McDougall et al., 1993). The fertilization wave initiates abruptly about 10-20 s after sperm egg fusion; once initiated, it rapidly propagates across the egg but until its onset, there is no sign of any calcium increase at the point of sperm-egg fusion (McDougall et al., 1993; Whitaker and Swann, 1993; Swann et al., 1994).

The sea urchin egg fertilization calcium transient involves both $\mathrm{InsP}_{3}$ and ryanodine receptors (Galione et al., 1993). Here, we confirm (see Mohri et al., 1995) that the $\mathrm{InsP}_{3}$ receptor is essential for the initiation and propagation of the fertilization calcium wave and, using confocal microscopy provide further evidence that the propagation rate of the calcium wave at fertilization in sea urchin embryos can be decreased by inhibitors of the $\mathrm{InsP}_{3}$ receptor and PLC $\gamma$. Once the wave is initiated, it propagates in a saltatory fashion by recruiting calcium release at calcium hot spots in the egg cytoplasm.

\section{MATERIALS AND METHODS}

Eggs of Lytechinus pictus were microinjected with calcium green dextran (Molecular probes, Eugene, USA) and fertilized at $16^{\circ} \mathrm{C}$ as described in Crossley et al. (1991) and McDougall et al. (1993). Inhibitors were microinjected as described in Crossley et al. (1991) and Shearer et al. (1999).

\section{RESULTS}

\subsection{The Ins $\mathrm{P}_{3}$ receptor and calcium wave initiation and propagation}

It has long been known that heparin, an $\operatorname{InsP}_{3} \mathrm{R}$ antagonist, markedly increases the latency of the fertilization response. The latency, or latent period, is defined as the time from the sperm-induced egg membrane depolarization to the onset of the calcium wave (Crossley et al., 1991). Figure 1 shows confocal images of the calcium increases in the egg at fertilization, measured using the calcium-sensitive dye, calcium green dextran. The early subcortical calcium increase is spherically symmetric and due to calcium influx through voltage gated calcium channels (McDougall et al., 1993). The fertilization calcium wave begins some $10 \mathrm{~s}$ after the initial calcium influx in this example; the latent period is thus comparable in length to the time it takes for the calcium wave to cross the egg, around $25 \mathrm{~s}$ in the example shown.

The latency of the fertilization response can also be increased by blocking PLC $\gamma$ using recombinant PLC $\gamma$ SH2 domains (Carroll et al., 1997, 1999; Shearer et al., 1999). Figure 2 shows that a concentration of $0.1-0.3$ $\mu \mathrm{M}$ SH2 domain construct in the egg cytoplasm produces an equivalent increase in latency to a concentration of heparin of around $300 \mu \mathrm{g} / \mathrm{mL}(30 \mu \mathrm{M})$. Note also that this concentration of heparin markedly increases the rise time of the fertilization calcium increase.

Figure 3 shows that the effect of heparin on the rise time reflects the slower kinetics of wave propagation in a heparin-injected egg (see Mohri et al., 1995). Both the rate of increase at the site of initiation and the rate of propagation across the egg are slowed. The peak calcium concentration at the site of sperm entry is between 6 and $9 \mathrm{~s}$ in the control egg. In the egg injected with $30 \mu \mathrm{M}$ heparin, the rise time so defined is between 20 and $30 \mathrm{~s}$. This can be seen both in the topographical representations of the respective calcium waves (figure $3 a$ ) and in the virtual line scans and time lines constructed from the images (figure $3 b, c)$. It is also evident that the spatial profile of the calcium wavefront is sharper in the heparin-injected egg, an indication that the propagation rate is markedly reduced (figure $3 a, b)$. This is confirmed in the rate of rise of calcium concentration at successive areas across the egg (figure 3c).

Figure 3 also shows an abortive calcium wave generated in an egg injected with $0.6 \mu \mathrm{M}$ PLC $\gamma$ SH2 domain inhibitory contruct (Shearer et al., 1999). The 

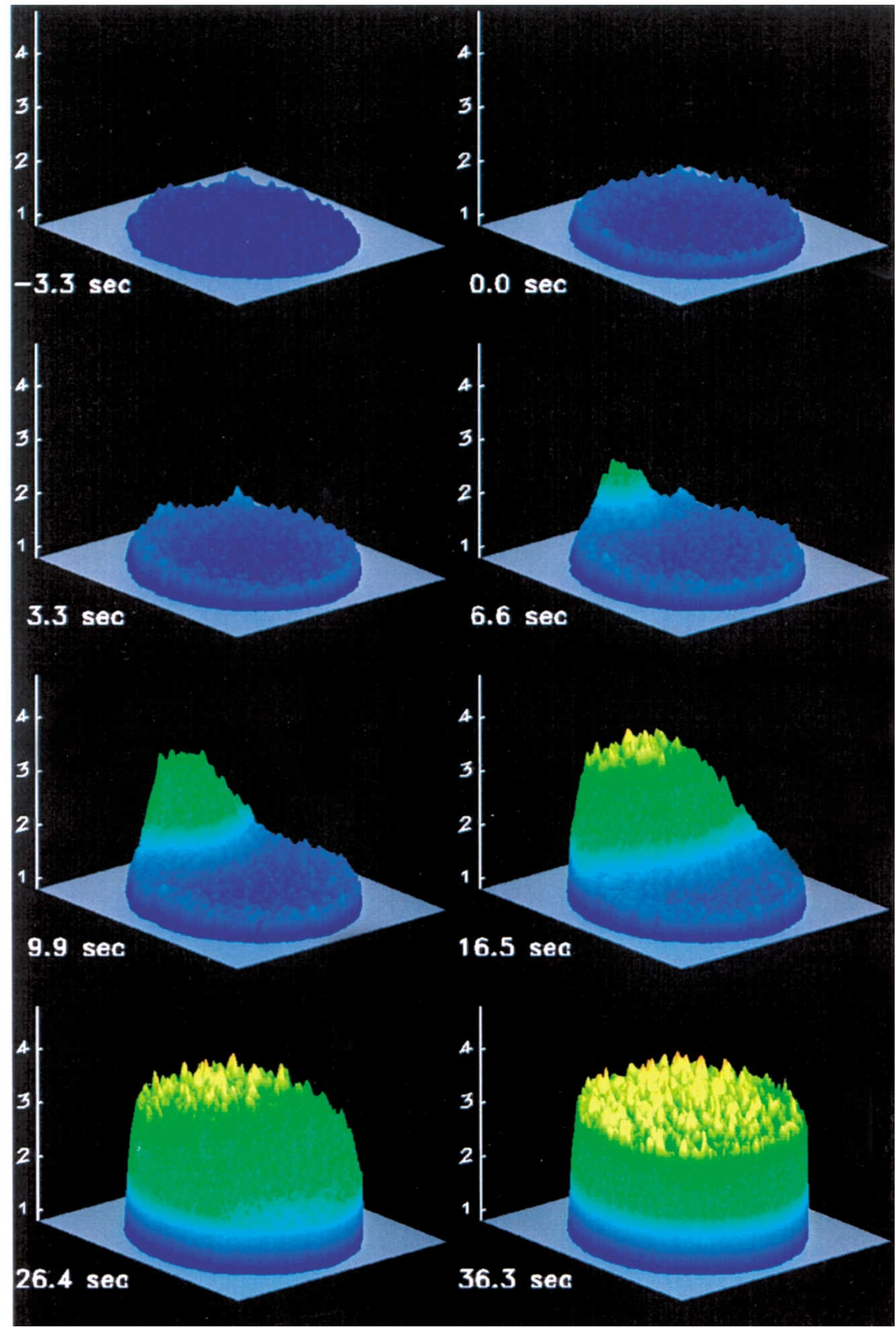

Figure 1. The fertilization calcium wave in the sea urchin egg, measured using calcium green dextran and fluorescence microscopy. An equatorial section of the egg is shown. Calcium concentration is indicated as the ratio increase in the calcium green dextran signal relative to the resting signal (McDougall et al., 1993). Note that the first indication of sperm-egg interaction is a small subcortical increase in intracellular free calcium concentration at $0 \mathrm{~s}$. Six seconds later, the calcium wave initiates and crosses the egg in 20-30 s. 


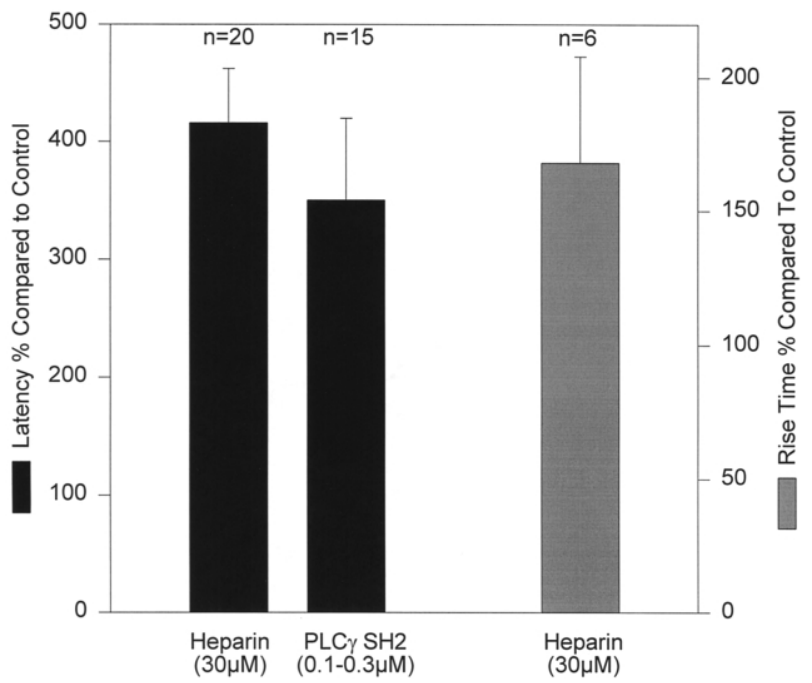

Figure 2. Blockers of the $\operatorname{lnsP}_{3}$ pathway can increase both the latency and the rise time of the fertilization response. The latency was measured by determining the time that elapsed between the small subcortical calcium increase and the onset of the fertilization wave. The rise time was measured from the onset of the wave to the peak of the calcium response.

rate of the initial increase cannot be determined precisely, as it occurs between confocal scans. However, rather than propagating across the egg, the calcium wave subsides in situ. This observation and the sharpening of the spatial profile in heparin-injected eggs (figure $3 a$ ) suggest that the propagation mechanism may be more sensitive to inhibition of the $\mathrm{InsP}_{3}$ pathway than the initiation mechanism.

These observations demonstrate that both initiation and propagation of the fertilization calcium wave depend primarily on the $\operatorname{Ins}_{3} \mathrm{R}$. It has already been shown that initiation of calcium wave requires both $\mathrm{InsP}_{3}$ (Crossley et al., 1991) and activation of PLC $\gamma$ (Shearer et al., 1999), since higher concentrations of both heparin $(170 \mu \mathrm{M})$ (Mohri et al., 1995) and the PLC $\gamma$ SH2 construct $(1 \mu \mathrm{M})$ (Shearer et al., 1999) completely block the regenerative calcium response at fertilization.

\subsection{Spatial heterogeneity of calcium wave propagation at fertilization}

It has been shown in a wide variety of cell types that calcium release occurs preferentially in small volumes of the cell. These observations have led to the idea that calcium release channels operate in functional clusters on the endoplasmic reticulum and that the channels within the clusters interact co-operatively. The kinetics of the $\mathrm{InsP}_{3} \mathrm{R}$ suggest that immediately adjacent receptors would be stimulated by calcium release from neighbouring receptors, while those further away would be inactivated (Adkins and Taylor, 1999). The notion is that, as a consequence, calcium waves are spatially heterogeneous: the wave propagates in a saltatory fashion from one active cluster to the next (Cheng et al., 1993; Parker and Yao, 1995; Lipp et al., 1997). We looked for evidence of this behaviour in the fertilization calcium wave.

The images of figures 1 and 3 suggest that calcium release is indeed spatially heterogeneous, since the surface of the calcium wave in topographical representations show a substructure of peaks of high calcium within the mountain range that builds as the wave develops. The data of figure 4 explore this heterogeneity further. The discontinuous nature of the propagating wave is most readily apparent when individual pixels are assigned to a colour band, depending on their value. Regions of spatially heterogeneous calcium increase then appear as promontories, peninsulas or islands ahead of or within the propagating wave. Examples are marked with asterisks. The spatial scale of the heterogeneities is similar to control eggs in eggs injected with either heparin or the PLC $\gamma \mathrm{SH} 2$ inhibitory construct (figure 4a), suggesting that the altered kinetics of the wave in the presence of $\operatorname{InsP}_{3}$ inhibitors are due to the rate of calcium release at discrete release sites that contribute in aggregate to the propagation of the wave.

Calcium release at an individual site is shown in figure $4 b$. The rate of rise of calcium concentration at the site is slow compared to the release sites identified in HeLa cells (Lipp et al., 1997), where release sites flicker on and off at the leading edge of the calcium transient within a 10-100 ms time scale. We can be confident that the gradual increase in calcium concentration at the hot spot shown in figure $4 b$ is not accompanied by substantial flicker: although images were captured only every $1.5 \mathrm{~s}$, the time taken to scan the hot spot was of the order of $100 \mathrm{~ms}$; it is very unlikely that the apparent slow monotonic increase in the hot spot could be due to sampling of a flickering hot spot. On the other hand, the temporal and spatial resolution of these measurements does not exclude the possibility that the slow increase may be due to the aggregate of calcium release from several flickering channels or channel clusters. The differences in time course may in part reflect the large increases in calcium concentration that occur during the fertilization wave relative to HeLa cells. However, it is also possible that the processes underlying the heterogeneity of calcium release in the sea urchin egg are fundamentally different to those described in other cell types. 


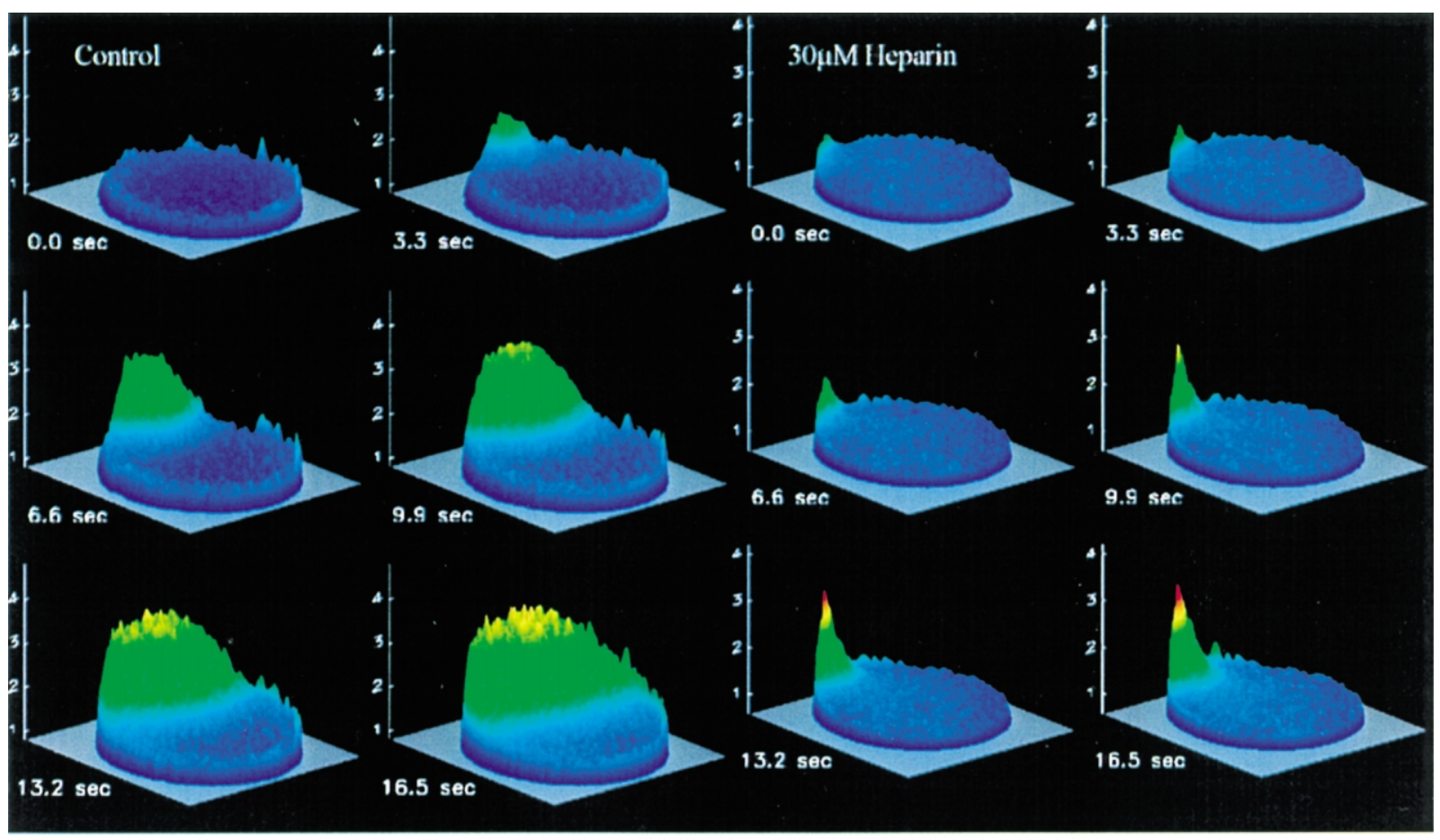

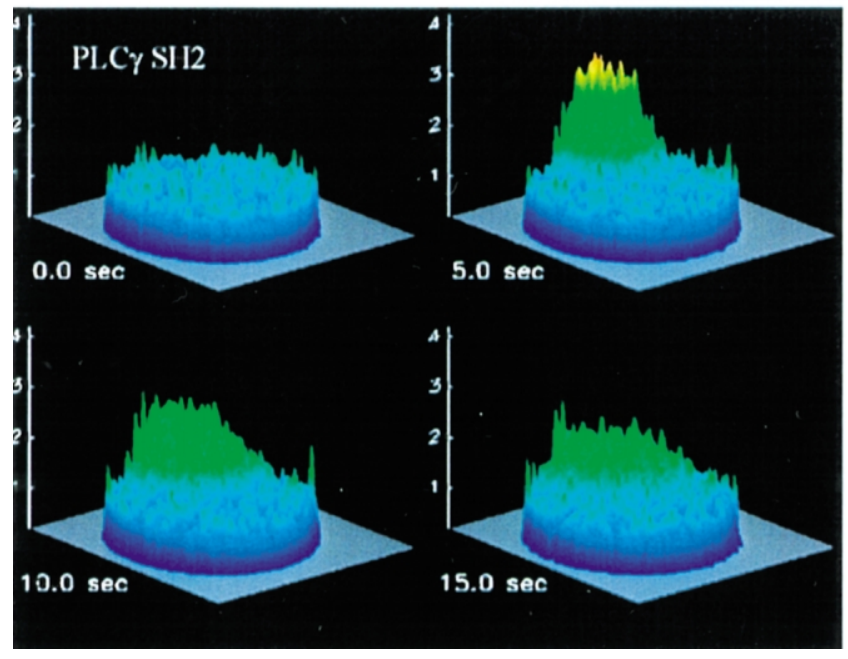

Figure 3. The effects of the $\operatorname{lns}_{3}$ antagonist heparin and the $\mathrm{SH} 2$ domain $\mathrm{PLC} \gamma$ inhibitor on the propagation of the calcium wave. Confocal imaging using calcium green dextran as in figure 1. a. Control, heparin $(30 \mu \mathrm{M})$ and PLC $\gamma$ $\mathrm{SH} 2$ domain construct $(0.6 \mu \mathrm{M})$. b. Line plots of the calcium increase with time in a band across the egg, indicated in the inset. c. Time course of the calcium increase at successive areas along the line shown in the inset.

\section{DISCUSSION}

The data presented here demonstrate that intermediate concentrations of blockers of the $\mathrm{InsP}_{3}$ calcium release pathway can alter both the latency of the onset of the calcium wave at fertilization in sea urchin embryos and its propagation. It has already been shown that the fertilization response can be completely abolished by both heparin (Mohri et al., 1995) and by inhibition of PLC $\gamma$ using dominant negative SH2 domain constructs (Carroll et al., 1999; Shearer et al., 1999). Thus, while the cyclic ADP ribose-ryanodine receptor pathway contributes to the propagation of the fertilization wave (Galione et al., 1993) in sea urchin eggs, the dominant initial messenger seems to be $\mathrm{InsP}_{3}$. Frog oocytes (Galione et al., 1993; Nuccittelli et al, 


\section{Control}

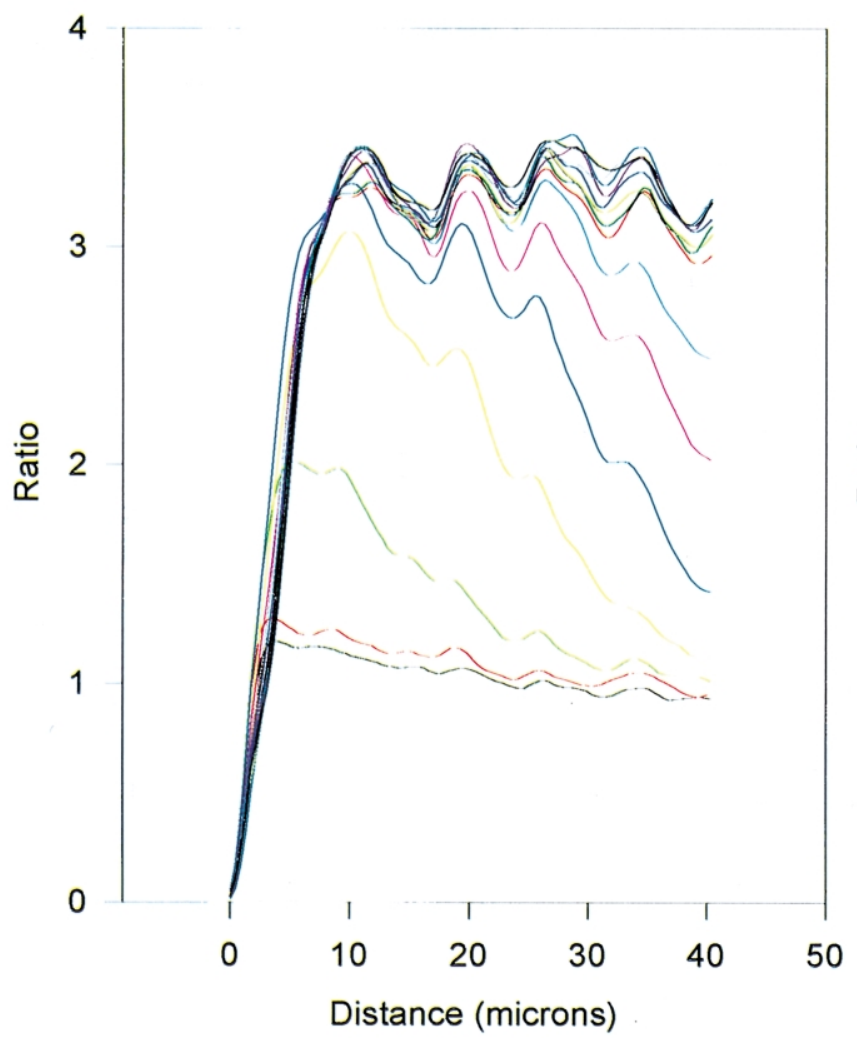

$30 \mu M$ Heparin Treated

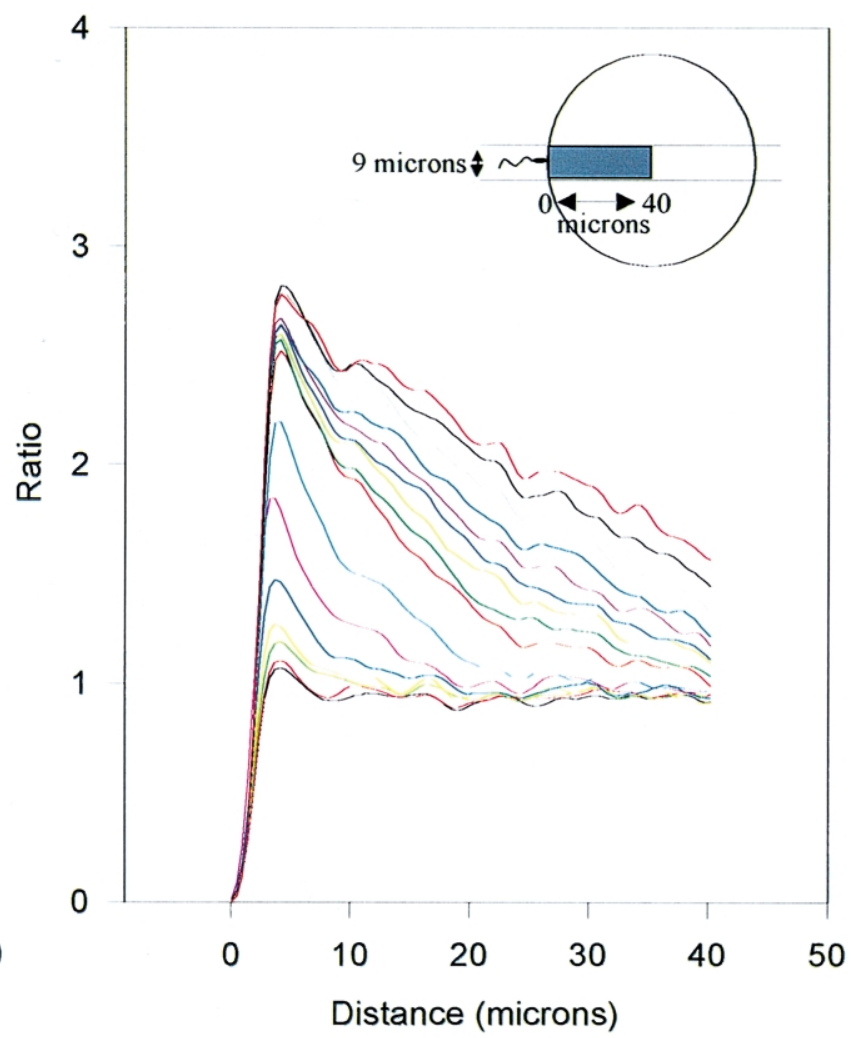

Figure 3. b. Line plots of the calcium increase with time in a band across the egg, indicated in the inset.

1993) are more sensitive to inhibition by heparin than mammalian oocytes (Kline and Kline, 1994) and the sea urchin egg, which results led to the conclusion that the former oocytes exhibited $\mathrm{InsP}_{3}$-only calcium waves, in contrast to the $\operatorname{InsP}_{3} /$ RyR waves of the sea urchin egg. On the other hand, ascidian oocytes are less sensitive to blockers of the InsP $\mathrm{P}_{3}$ receptor than to PLC $\gamma$ inhibitions (McDougall and Sardet, 1995; Yoshida et al., 1998; Runft and Jaffe, 2000). Our confocal imaging data confirm previous reports (Mohri et al., 1995) and show that the sea urchin egg calcium wave is utterly dependent on the $\mathrm{InsP}_{3}$ pathway. It seems that the distinction between oocytes based on their reliance of $\mathrm{InsP}_{3} \mathrm{R}$ and RyR at fertilization is more likely to be quantitative than qualitative and that the calcium wave in all the oocytes discussed is almost certainly due, at least initially, to the production of $\operatorname{InsP}_{3}$.

Our data also show that the calcium wave propagates in a saltatory way in the sea urchin egg at fertilization by spreading between what appear to be discrete release sites. In this, they resemble calcium waves in heart, in mammalian cells in culture and in smooth muscle (Cheng et al., 1993; Parker and Yao, 1995; Lipp et al., 1997; Radding et al., 1999; Jaggar et al., 2000). The release sites in the sea urchin egg show slow release kinetics compared to those observed in other cells. This may be due simply to the magnitude of calcium release during the fertilization wave; it may be, though, that the sea urchin egg release sites are structurally defined as a cluster of release channels, rather than being functionally defined as clusters of unduly active channels (Cheng et al., 1993; Lipp et al., 1997). The magnitude and spatial extent of calcium release is comparable to the calcium puffs observed in Xenopus oocytes (Parker and Yao, 1995).

Acknowledgments. We thank Michael Aitchison for help in preparing the figures. This work was supported by the Wellcome Trust. 


\section{Control}

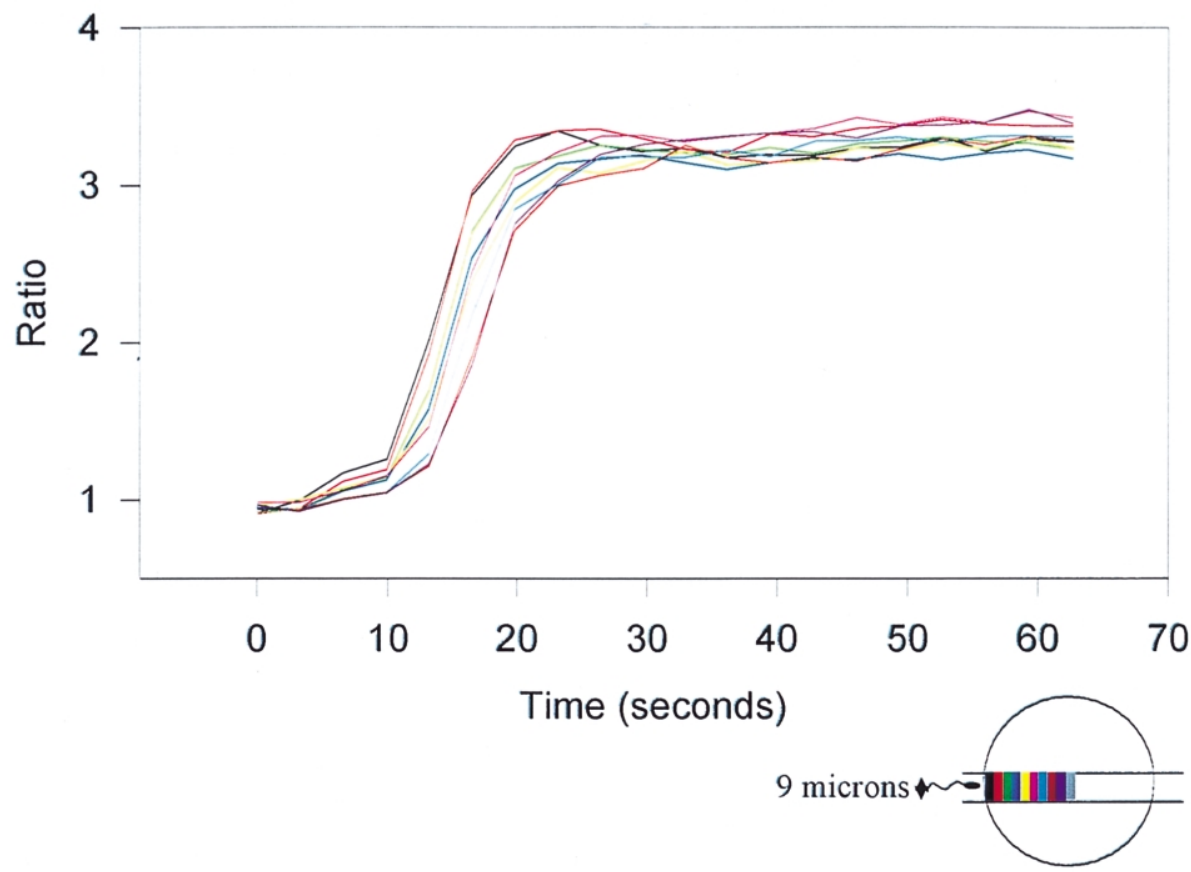

Each coloured line corresponds to the coloured area $(9 \mu \mathrm{m} \times 2 \mu \mathrm{m})$ shown.

\section{Heparin}

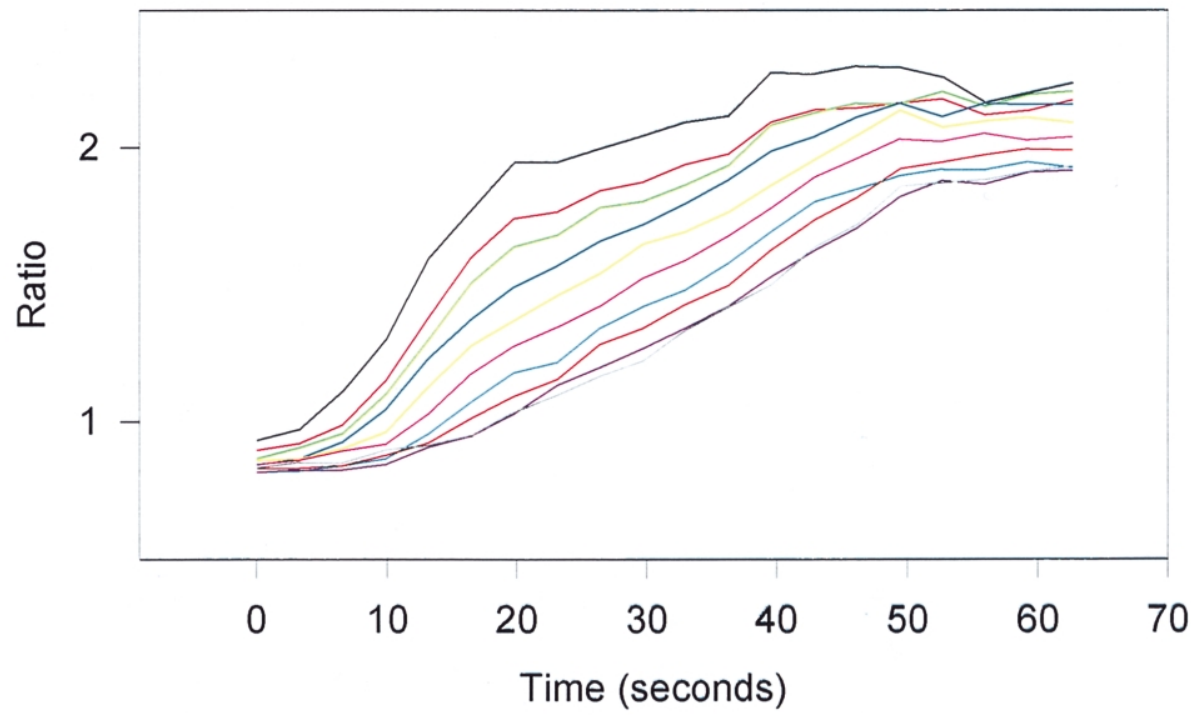

Figure 3. c. Time course of the calcium increase at successive areas along the line shown in the inset. 
a
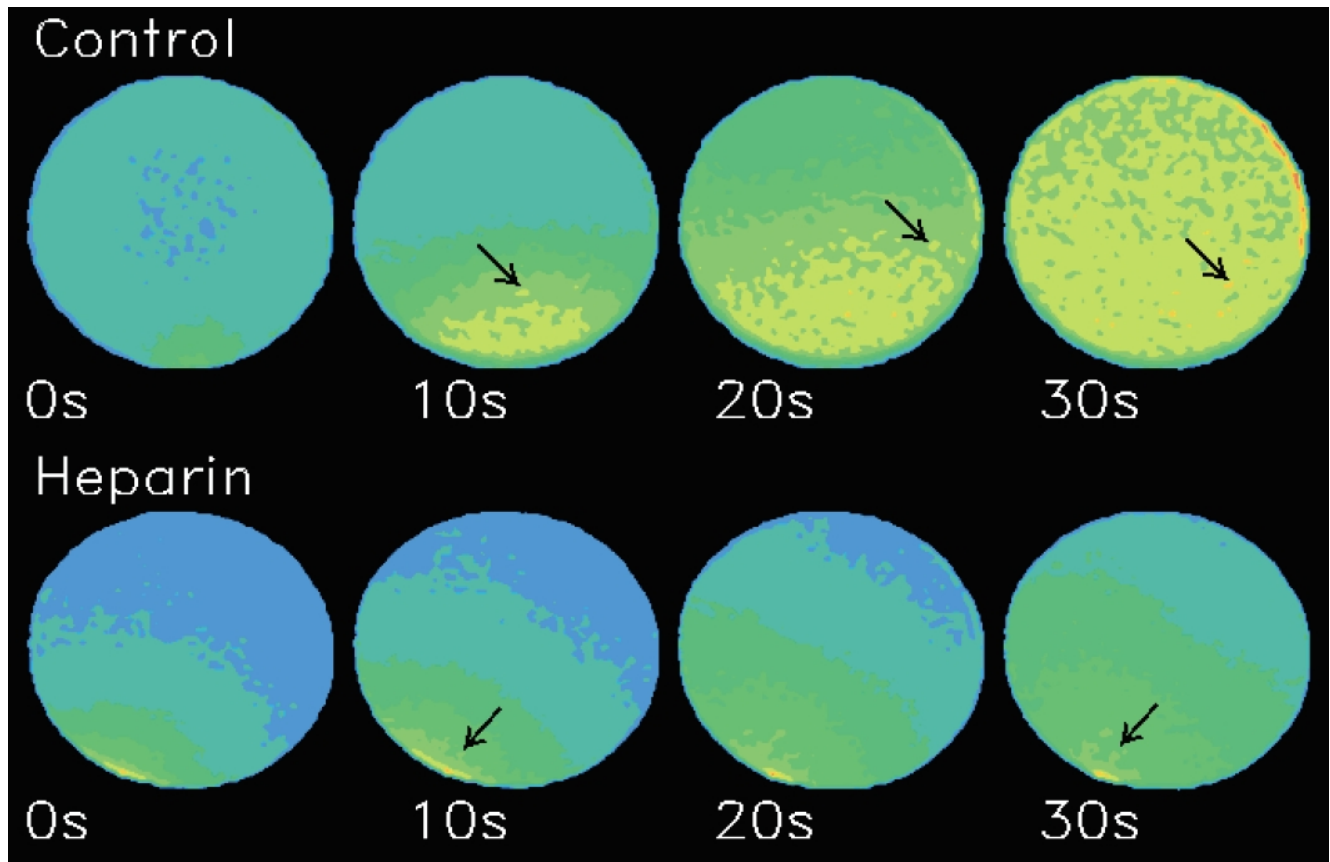

\section{PLCy $\mathrm{SH} 2$}
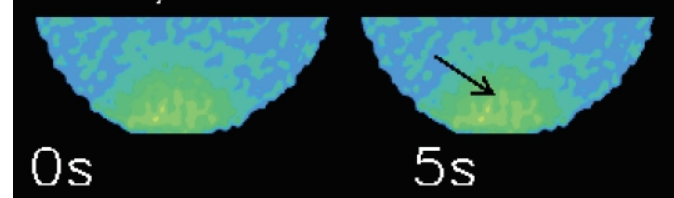

$5 s$
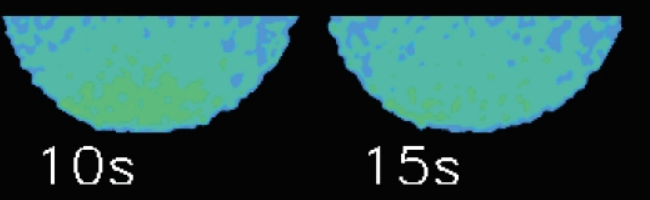

1

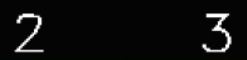

\section{Ratio}

Figure 4. Spatial substructure of the fertilization calcium wave. a. The images have been processed using a discontinuous look up table that assigns each pixel to a colour band. The colours correspond to the ratios shown in figures 1 and 3 . Note that the discrete release sites, some of which are indicated by asterisks, can be followed in successive frames. This is particularly evident in the egg injected with the PLC $\gamma$ SH2 construct, where two sites remain active as the abortive wave subsides. $\mathbf{b}$. Contour map of the ratio confocal image of a single discrete calcium release site as the calcium wave reaches its peak. Note the spatial dimensions and the slow kinetics. 

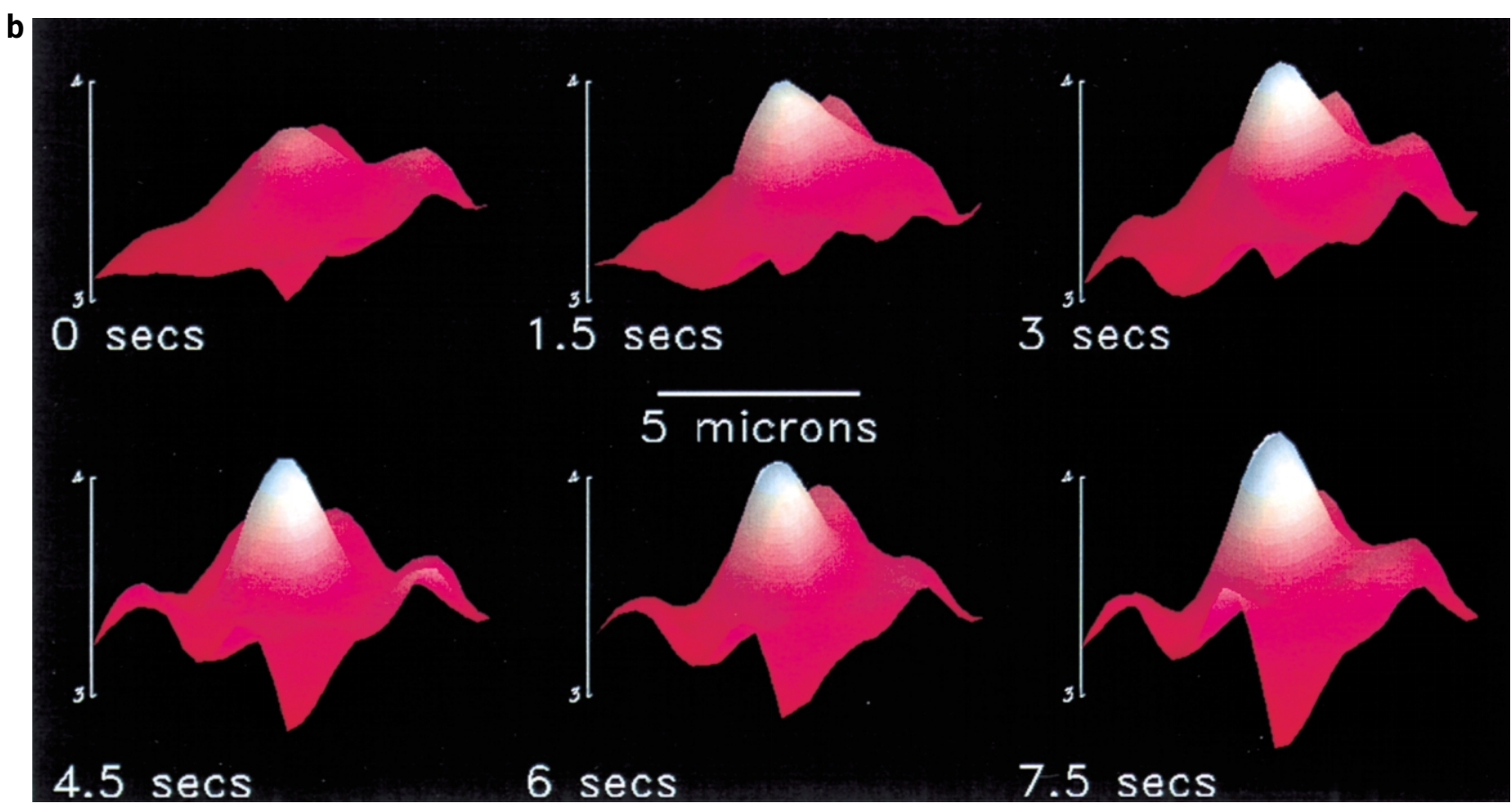

Figure 4. Continued.

\section{REFERENCES}

Abassi, Y.A., Carroll, D.J., Giusti, A.F., Belton, R.J. Jr., Foltz, K.R., 2000. Evidence that Src-type tyrosine kinase activity is necessary for initiation of calcium release at fertilization in sea urchin eggs. Dev. Biol. 218, 206-219.

Adkins, C.E., Taylor, C.W., 1999. Lateral inhibition of inositol 1,4,5trisphosphate receptors by cytosolic $\mathrm{Ca}^{2+}$. Curr. Biol. 9, 1115-1118.

Carroll, D.J., Ramarao, C.S., Mehlmann, L.M., Roche, S., Terasaki, M., Jaffe, L.A., 1997. Calcium release at fertilization in starfish eggs is mediated by phospholipase C $\gamma$. J. Cell Biol. 138, 1303-1311.

Carroll, D.J., Albay, D.T., Terasaki, M., Jaffe, L.A., Foltz, K.R., 1999. Identification of PLCgamma-dependent and -independent events during fertilization of sea urchin eggs. Dev. Biol. 206, 232-247.

Chambers, E.L., de Armendi, J., 1979. Membrane potential, action potential and activation potential of eggs of the sea urchin, Lytechinus variegatus. Exp. Cell Res. 122, 203-218.

Cheng, H., Lederer, W.J., Cannell, M.B., 1993. Calcium sparks: elementary events underlying excitation-contraction coupling in heart muscle. Science 262, 740-744.

Ciapa, B., Epel, D., 1991. A rapid change in phosphorylation on tyrosine accompanies fertilization of sea urchin eggs. FEBS Lett. 295, 167-170.

Ciapa, B., Borg, B., Whitaker, M.J., 1992. Polyphosphoinositide metabolism during the fertilization wave in sea urchin eggs. Development $115,187-195$.

Crossley, I., Whalley, T., Whitaker, M.J., 1991. Guanosine 5'thiotriphosphate may stimulate phosphoinositide messenger production in sea urchin eggs by a different route than the fertilizing sperm. Cell Regul. 2, 121-133.

David, C., Halliwell, J., Whitaker, M.J., 1988. Some properties of the membrane currents underlying the fertilization potential in sea urchin eggs. J. Physiol. 402, 139-154.

Galione, A., McDougall, A., Busa, W.B., Willmott, N., Gillot, I., Whitaker, M.J., 1993. Redundant mechanisms of calcium-induced calcium release underlie calcium waves during fertilization. Science $261,348-352$.
Giusti, A.F., Carroll, D.J., Abassi, Y.A., Foltz, K.R., 1999. Evidence that a starfish egg Src family tyrosine kinase associates with PLC-gamma1 SH2 domains at fertilization. Dev. Biol. 208, 189-199.

Giusti, A.F., Carroll, D.J., Abassi, Y.A., Terasaki, M., Foltz, K.R., Jaffe, L.A., 1999b. Requirement of a Src family kinase for initiating calcium release at fertilization in starfish eggs. J. Biol. Chem. 274, 29318-29322.

Glahn, D., Mark, S.D., Behr, R.K., Nuccitelli, R., 1999. Tyrosine kinase inhibitors block sperm-induced egg activation in Xenopus laevis. Dev. Biol. 205, 171-180.

Jaffe, L.A., 1976. Fast block to polyspermy in sea urchin eggs is electrically mediated. Nature 261, 68-71.

Jaggar, J.H., Porter, V.A., Lederer, W.J., Nelson, M.T., 2000. Calcium sparks in smooth muscle. Am. J. Physiol. Cell Physiol. 278, C235-C256

Jones, K.T., Cruttwell, C., Parrington, J., Swann, K., 1998. A mammalian sperm cytosolic phospholipase $\mathrm{C}$ activity generates inositol trisphosphate and causes $\mathrm{Ca}^{2+}$ release in sea urchin egg homogenates. FEBS Lett. 437, 297-300.

Jones, K.T., Matsuda, M., Parrington, J., Katan, M., Swann, K., 2000. Different $\mathrm{Ca}^{2+}$-releasing abilities of sperm extracts compared with tissue extracts and phospholipase $C$ isoforms in sea urchin egg homogenate and mouse eggs. Biochem. J. 346, 743-749.

Kline, J.T., Kline, D., 1994. Regulation of intracellular calcium in the mouse egg: Evidence for inositol trisphosphate-induced calcium release but not calcium-induced calcium release. Biol. Reprod. 50, 193-203.

Kyozuka, K., Deguchi, R., Mohri, T., Miyazaki, S., 1998. Injection of sperm extract mimics spatiotemporal dynamics of $\mathrm{Ca}^{2+}$ responses and progression of meiosis at fertilization of ascidian oocytes. Development 125, 4099-4105.

Lawrence, Y., Whitaker, M., Swann, K., 1997. Sperm-egg fusion is the prelude to the initial $\mathrm{Ca}^{2+}$ increase at fertilization in the mouse. Development 124, 233-241. 
Lee, S.J., Shen, S.S., 1998. The calcium transient in sea urchin eggs during fertilization requires the production of inositol 1,4,5trisphosphate. Dev. Biol. 193, 195-208.

Lee, S.J., Madden, P.J., Shen, S.S., 1998. U73122 blocked the cGMPinduced calcium release in sea urchin eggs. Exp. Cell Res. 242, 328-340.

Lipp, P., Thomas, D., Berridge, M.J., Bootman, M.D., 1997. Nuclear calcium signalling by individual cytoplasmic calcium puffs. EMBO J. $16,7166-7173$

Lynn, J.W., Chambers, E.L., 1984. Voltage clamp studies of fertilization in sea urchin eggs. I. Effect of clamped membrane potential on sperm entry, activation, and development. Dev. Biol. 102, 98-109.

Lynn, J.W., McCulloh, D.H., Chambers, E.L., 1988. Voltage clamp studies of fertilization in sea urchin eggs. II. Current patterns in relation to sperm entry, nonentry, and activation. Dev. Biol. 128, 305-323.

McCulloh, D.H., Chambers, E.L., 1992. Fusion of membranes during fertilization. Increases of the sea urchin egg's membrane capacitance and membrane conductance at the site of contact with the sperm. J. Gen. Physiol. 99, 137-175.

McDougall, A., Sardet, C., 1995. Function and characteristics of repetitive calcium waves associated with meiosis. Curr. Biol. 5, 318-328.

McDougall, A., Gillot, I., Whitaker, M.J., 1993. Thimerosal reveals calcium-induced calcium release in unfertilized sea urchin eggs. Zygote 1, 35-42.

Mehlmann, L.M., Carpenter, G., Rhee, S.G., Jaffe, L.A., 1998. SH2 domain-mediated activation of phospholipase Cgamma is not required to initiate $\mathrm{Ca}^{2+}$ release at fertilization of mouse eggs. Dev. Biol. 203, 221-232.

Miyazaki, S., Yuzaki, M., Nakada, K., Shirakawa, H., Nakanishi, S., Nakade, S., Mikoshiba, K., 1992. Block of $\mathrm{Ca}^{2+}$ wave and $\mathrm{Ca}^{2+}$ oscillation by antibody to the inositol 1,4,5-trisphosphate receptor in fertilized hamster. Science 257, 251-255.

Miyazaki, S., Shirakawa, H., Nakada, K., Honda, Y., 1993. Essential role of the inositol 1,4,5-trisphosphate receptor $/ \mathrm{Ca}^{2+}$ release channel in $\mathrm{Ca}^{2+}$ waves and $\mathrm{Ca}^{2+}$ oscillations at fertilization of mammalian eggs. Dev. Biol. 158, 62-78.

Mohri, T., Ivonnet, P.I., Chambers, E.L., 1995. Effects on sperm-induced activation current and increase of cytosolic $\mathrm{Ca}^{2+}$ by agents that modify the mobilization of $\left[\mathrm{Ca}^{2+}\right]_{\mathrm{i}}$. Dev. Biol. 172, 139-157.
Nuccitelli, R., Yim, D.L., Smart, T., 1993. The sperm-induced $\mathrm{Ca}^{2+}$ wave following fertilization of the Xenopus egg requires the production of Ins $(1,4,5) \mathrm{P}_{3}$. Dev. Biol. 158, 200-212.

Parker, I., Yao, Y., 1995. Calcium puffs in Xenopus oocytes. Ciba Found. Symp. 188, 50-60.

Radding, W., Jordan, S.E., Hester, R.B., Blair, H.C., 1999. Intracellular calcium puffs in osteoclasts. Exp. Cell Res. 253, 689-696.

Runft, L.L., Jaffe, L.A., 2000. Sperm extract injection into ascidian eggs signals $\mathrm{Ca}^{2+}$ release by the same pathway as fertilization. Development 127, 3227-3236.

Shearer, J., De Nadai, C., Emily-Fenouil, F., Gache, C., Whitaker, M., Ciapa, B., 1999. Role of phospholipase $\mathrm{C} \gamma$ at fertilization and during mitosis in sea urchin eggs and embryos. Development 126, 2273-2284.

Shen, S.S., Kinsey, W.H., Lee, S.J., 1999. Protein tyrosine kinasedependent release of intracellular calcium in the sea urchin egg. Dev. Growth Differ. 41, 345-355.

Snow, P., Yim, D.L., Leibow, J.D., Saini, S., Nuccitelli, R., 1996. Fertilization stimulates an increase in inositol trisphosphate and inositol lipid levels in Xenopus eggs. Dev. Biol. 180, 108-118.

Speksnijder, J.E., Sardet, C., Jaffe, L.F., 1990. The activation wave of calcium in the ascidian egg and its role in ooplasmic segregation. J. Cell Biol. 110, 1589-1598.

Stricker, S.A., 1995. Time-lapse confocal imaging of calcium dynamics in starfish embryos. Dev. Biol. 170, 496-518.

Swann, K., 1993. The soluble sperm oscillogen hypothesis. Zygote 1, 273-276.

Swann, K., Whitaker, M.J., 1986. The part played by inositol trisphosphate and calcium in the propagation of the fertilization wave in sea urchin eggs. J. Cell Biol. 103, 2333-2342.

Swann, K., McDougall, A., Whitaker, M.J., 1994. Calcium signalling at fertilization. J. Mar. Biol. Assoc. UK 74, 3-16.

Whitaker, M.J., Steinhardt, R.A., 1982. Ionic regulation of egg activation. Q. Rev. Biophys. 15, 593-666.

Whitaker, M.J., Swann, K., 1993. Lighting the fuse at fertilization. Development 117, 1-12.

Yoshida, M., Sensui, N., Inoue, T., Morisawa, M., Mikoshiba, K., 1998. Role of two series of $\mathrm{Ca}^{2+}$ oscillations in activation of ascidian eggs. Dev. Biol. 203, 122-133. 